\title{
HUBUNGAN ANTARA AKTIVITAS FISIK DENGAN NYERI PUNGGUNG BAWAH PADA PERAWAT DI RUMAH SAKIT UMUM DAERAH LUWUK BANGGAI
}

\author{
Mario Esau Katuuk \\ Michael Karundeng \\ Program Studi Ilmu Keperawatan Fakultas Kedokteran \\ Universitas Sam Ratulangi \\ Email : rioesau@unsrat.ac.id
}

\begin{abstract}
Low back pain is major cause of disability in workers, and nurses is one of a profession that is more susceptible to get low back pain, its because of risk factors severe physical activity such as lifting medical equipment, lifting patients, and moving patients. The purpose of this study is to know relationship between physical activity and low back pain in nurses at Rumah Sakit Umum Daerah Luwuk Banggai. The method of this study uses cross sectional study design. The sample of this study amounted to 100 nurses with random sampling method, and to determine sample size, using Lameshow formula. The results of this study, out of 100 nurses most of them were diagnosed with low back pain (58\%) and have serve physical activity (41\%) by using the chi-square test at significance level of 95\%, it was found that pvalue was 0.001 smaller than significant value of 0.05. In conclusion of this study, there is significant relationship between physical activity and low back pain in nurses at Rumah Sakit Umum Daerah Luwuk Banggai.
\end{abstract}

Keywords: Low Back Pain, Physical Activity, Nurse.

Abstrak : Nyeri punggung bawah merupakan penyebab utama kecacatan pada pekerja, dan perawat adalah salah satu profesi yang lebih rentan terkena Nyeri punggung bawah, dikarenakan salah satu faktor resiko yaitu aktivitas fisik yang berat seperti mengangkat peralatan medis, mengangkat pasien, dan memindahkan pasien. Tujuan studi ini untuk mengetahui hubungan antara aktivitas fisik dengan nyeri punggung bawah pada perawat di Rumah Sakit Umum Daerah Luwuk Banggai. Metode studi ini menggunakan desain penelitian cross-sectional. Sampel studi ini berjumlah 100 perawat dengan metode pengambilan sampel random sampling, dan untuk menentukan besarnya sampel menggunakan rumus Lameshow. Hasil dari penelitian ini, didapatkan dari 100 perawat yang diteliti sebagian besar terdiagnosa nyeri punggung bawah (58\%) dan memiliki aktivitas fisik yang berat (41\%), dengan menggunakan uji chi-square pada tingkat kemaknaan 95\%, didapat bahwa nilai p-value adalah 0,001 lebih kecil dari nilai signfikan 0,05. Kesimpulan dari penelitian ini bahwa terdapat hubungan yang signifikan antara aktivitas fisik dan nyeri punggung bawah pada perawat di Rumah Sakit Umum Daerah Luwuk Banggai.

Kata Kunci : Nyeri Punggung Bawah, Aktivitas Fisik, Perawat. 


\section{PENDAHULUAN}

Nyeri merupakan rasa yang tidak menyenangkan dan menimbulkan ketidaknyamanan yang dirasakan dalam pikiran dan timbul di bagian tubuh, Nyeri juga merupakan sensasi individual yang unik, rumit, dan universal (Asmadi, 2008). Nyeri dapat timbul diberbagai bagian tubuh dan dapat diakibatkan oleh banyak hal, salah satunya seperti kondisi kerja dengan aktivitas yang padat, kondisi ini dapat menyebabkan stress fisik yang berlebihan pada sumsum tulang belakang sehingga menyebabkan spasme otot dan membuat saraf terhimpit dan timbulah rasa nyeri pada bagian punggung bawah. Nyeri punggung bawah terjadi di bawah tulang rusuk ke-12 dan di atas lipatan gluteal. Nyeri punggung bawah sering diakibatkan asimetri minor columna vertebralis, terutama regio lumbosakral (Gibson,2012).

Keluhan Nyeri punggung bawah dapat terjadi pada setiap orang Pekerjaan yang beresiko terkena Nyeri punggung bawah antara lain petani, operator alat berat, dan peerawat (World Health Organization, 2018).Perawat memiliki resiko yang tinggi dan lebih rentan untuk terkena Nyeri punggung bawah, studi penelitian yang dilakukan di Bangladesh menunjukan seorang perawat beresiko tinggi terkena Nyeri punggung bawah dengan total sebanyak $72,9 \%$ dari 229 orang perawat mengalami Nyeri punggung bawah (Sanjoy et al, 2017). Studi penelitian di Slovenia menunjukan hasil sebanyak $85,9 \%$ dari 1744 perawat mengalami Nyeri punggung bawah (Savic \& Touzery, 2017). Studi sebelumnya di Turki prevalensi perawat yang megalami Nyeri punggung bawah tercatat 84,2\% dari 114 orang (Ovayolu et al, 2014), pada tahun yang sama dilakukan juga studi di Iran mengenai prevalensi perawat yang mengalami Nyeri punggung bawah dan tercatat sebanyak $75,4 \%$ dari 1246 orang perawat mengalami Nyeri punggung bawah baik akut maupun kronik (Rezaee \& Ghasemi, 2014). Tunisia dan Taiwan juga melakukan studi yang sama, di Tunisia ditemukan hasil bahwa sebanyak
58,1\% dari 203 perawat mengalami Nyeri punggung bawah (Boughattas et al, 2017) dan Taiwan terdapat sebanyak $72 \%$ dari 567 orang perawat mengalami Nyeri punggung bawah (Shwn-Huey et al, 2016). Studi ini juga telah dilaksanakan di RSUP Prof.Dr.R.D. Kandou Manado dan hasilnya terdapat sebanyak $86 \%$ dari 43 responden mengalami Nyeri punggung bawah (Goni, 2016). Banyak perawat yang terkena Nyeri punggung bawah diakibatkan oleh salah satu faktor resiko yaitu aktivitas fisik yang berat seperti mengangkat peralatan medis, mengangkat pasien, dan memindahkan pasien (Sanjoy et al, 2017). Aktifitas fisik juga memiliki resiko lebih besar dari usia dan jenis kelamin seorang perawat (Rezaee \& Ghasemi, 2014), berdiri dengan cukup lama, membungkuk, mengubah posisi pasien juga merupakan aktifitas fisik yang dilakukan oleh perawat (Ovayolu et al, 2014).

Studi pendahuluan yang dilakukan pada perawat di Rumah Sakit Umum Daerah Luwuk Banggai, menunjukan perawat yang bekerja disana melakukan aktivitas fisik dengan cukup berat seperti mengangkat dan memindahkan pasien dari tempat tidur, berdiri dengan lama dengan posisi membungkuk untuk melakukan tindakan pembersihan luka, mendorong kursi roda membawa pasien menaiki jalan menanjak dikarenakan masih kurangnya fasilitas lift untuk mempermudah akses jalan. Perawat di setiap ruang rawat inap rumah sakit melakukan banyak pekerjaan dengan berbagai tugas dan tanggung jawab. Perawat melakukan aktivitas fisik seperti mengangkatan benda berat, memindahkan pasien, mengubah posisi pasien. Perawat yang bekerja di Rumah Sakit Umum Luwuk Banggai terdapat sebanyak 281 orang. Hasil wawancara awal dengan perawat disana, sebanyak 130 orang perawat mengatakan mereka merasakan nyeri punggung bagian bawah, yang menyebar kebagian bawah, skala nyeri yang dirasakan bervariasi antara 4 sampai dengan 7. Berdasarkan fenomena ini, peneliti tertarik untuk melakukan penelitian untuk melihat apakah ada 
hubungan aktifitas fisik dengan kejadian Nyeri punggung bawah pada perawat di Rumah Sakit Umum Daerah (RSUD) Kota Luwuk Banggai, dari penelitian ini juga telah diketahui tingkat aktivitas fisik yang dilakukan oleh perawat RSUD Luwuk Banggai, Prevalensi Perawat yang terdiagnosa nyeri punggung bawah dan teranalisis hubungan antara kedua variabel. Melalui penelitian ini juga diharapkan dapat memberikan manfaat bagi perawat, pendidikan keperawatan dan peneliti selanjutnya.

\section{METODE PENELITIAN}

Jenis penelitian yang digunakan ialah penelitian yang bersifat analitik dengan pendekatan cross sectional. Penelitian ini dilakukan di Rumah Umum Daerah Luwuk Banggai pada tanggal 3 Oktober - 4 Desember tahun 2018 dengan populasi sebanyak 281 orang. Pengambilan sampel pada penelitian ini dilakukan secara non probability sampling dengan teknik Random sampling. Penentuan besar sampel menggunakan rumus Lameshow didapatkan sampel pada penelitian ini adalah 100 orang yang telah memenuhi kriteria inklusi : Perawat yang bekerja di Rumah Sakit Umum Daerah Luwuk Banggai, Perawat yang bersedia menjadi responden, Perawat dengan rentang usia 22 - 55 Tahun, Perawat yang bekerja di ruangan rawat inap. Kriteria eksklusi : Perawat yang tidak dapat ditemui selama penelitian berlangsung (misalnya karena sakit atau izin), Perawat yang sedang hamil, Perawat yang menderita herniasi nukleus pulposus (HNP), Perawat yang mempunyai deformitas tulang belakang, Perawat yang pernah atau sedang mengalami trauma daerah punggung bawah, Osteoporosis, dan Riwayat Operasi Tulang Belakang.

Penelitian ini menggunakan instrumen berupa kuesioner data diri, tingkat aktivitas fisik yang terdiri dari 15 item pertanyaan, yang dibagi dalam 3 bagian, bagian pertama untuk mengukur aktivitas fisik selama jam kerja, bagian kedua selama diluar jam kerja dan bagian ketiga selama waktu senggang, dengan isian dibagi dalam tiga kategori yaitu tidak pernah, kadang-kadang, dan sering dimana aktivitas fisik rendah dengan skor 1-20, aktivitas fisik sedang skor 21-41, aktivitas fisik tinggi skor $42-60$, dan kuesioner nyeri punggung bawah sebagai alat screening awal yang terdiri dari 10 pertanyaan, dibagi dalam dua kategori ya dan tidak jika reponden menjawab ya sebanyak lebih dari sama dengan 5 pertanyaan, maka responden tersebut dikonsultasikan ke dokter untuk didiagnosa.Jenis data yang digunakan pada penelitian ini adalah data primer dan data sekunder. Data primer adalah data yang diperoleh langsung dari responden dan data sekunder data yang diperoleh dari dokter rehabilitasi medik Rumah Sakit Umum Daerah Luwuk Banggai berupa hasil diagnosa.

Pengolahan data yang diperoleh dari hasil penelitian ini diolah secara manual dengan mengelompokkan hasil dari lembar kuesioner yang dibagikan dan selanjutnya dilakukan analisis menggunakan uji statistik. Setelah itu diolah menggunakan sistem komputerisasi, tahap-tahap tersebut yaitu Editting, Coding, Proccessing, dan Cleaning. Analisis univariat pada penelitian ini akan menghasilkan distribusi frekuensi yang memberi gambaran mengenai jumlah dan presentase. Analisis univariat dilakukan untuk menganalisa variabel Aktivitas Fisik dan variabel Nyeri Punggung Bawah. Analisa bivariat yang digunakan adalah hasil tabulasi silang. Untuk menguji hipotesa dilakukan analisa statistik dengan uji Chi-square pada tingkat kemaknaan 95\% ( $\rho$ - Value < 0,05), setelah diuji hasil memenuhi syarat dan ditarik suatu kesimpulan, dimana nilai $\rho-$ Value lebih kecil dari nilai $\alpha(0,05)$, maka sesuai dengan Hipotesis awal bahwa ada hubungan yang signifikan antara variabel dependen dengan variabel independen. 
HASIL dan PEMBAHASAN

Tabel 1. Distribusi responden berdasarkan Nyeri Punggung Bawah.

\begin{tabular}{ccc}
\hline $\begin{array}{c}\text { Nyeri Punggung } \\
\text { Bawah }\end{array}$ & n & \% \\
\hline Tidak Terdiagnosa & 42 & 42 \\
Terdiagnosa & 58 & 58 \\
\hline Total & $\mathbf{1 0 0}$ & $\mathbf{1 0 0 , 0}$ \\
\hline
\end{tabular}

Sumber : Data Sekunder, 2018

Melalui tabel dilihat bahwa dari 100 responden sebagian besar responden terdiagnosa nyeri punggung bawah, yaitu sebesar $58 \%$ sendangkan $42 \%$ diantaranya tidak terdiagnosa nyeri punggung bawah. Nyeri punggung bawah terjadi akibat perawat mengalami penekanan nervus dibagian lumbalis sehingga perawat merasakan nyeri dibagian punggung bawah (Satyanegara et al, 2010). Nyeri punggung bawah banyak terjadi pada perawat dan diakibatkan oleh banyak hal, salah satunya seperti kondisi kerja dengan posisi tubuh menunduk ke depan, bahu melengkung ke depan, mengangkat benda berat, bersamaan dengan aktivitas yang padat, kondisi ini dapat menyebabkan stress fisik yang berlebihan pada sumsum tulang belakang sehingga menyebabkan spasme otot dan membuat saraf terhimpit sehingga timbulah rasa nyeri pada bagian punggung bawah (Gibson, 2012).

Hasil studi juga ditemukan bahwa aktivitas perawat di RSUD Luwuk Banggai sebagian besar sering mengangkat pasien, memindahkan pasien, jarang beristirahat sehabis melakukan tindakan, berolahraga berat diluar jam dinas dan jarang beritirahat Hasil studi ini juga sesuai dengan beberapa studi mengenai prevalensi perawat terkena nyeri punggung bawah, di Bangladesh terdapat $72,9 \%$ dari 229 orang perawat mengalami Nyeri punggung bawah (Sanjoy et al, 2017). Penelitian yang sama di Slovenia juga menunjukan hasil sebanyak 85,9\% dari 1744 (Savic \& Touzery, 2017). Kemudian studi di Turki tercatat $84,2 \%$ dari 114 orang (Ovayolu, Genc et al, 2014), dan di Manado penelitian pernah dilakukan di RSUP Prof Kandou dengan hasil sebanyak
$86 \%$ perawat mengalami nyeri punggung bawah (Goni, 2016).

Berdasarkan hasil studi dan teori pendukung, Peneliti berasumsi bahwa hal ini dapat terjadi diakibatkan oleh aktivitas fisik yang cukup tinggi, seperti sering mengangkat pasien, memindahkan pasien, jarang beristirahat sehabis melakukan tindakan, berolahraga berat diluar jam dinas dan jarang beritirahat. Kesimpulan dari hasil studi ini bahwa profesi perawat memiliki resiko dan prevalensi kejadian nyeri punggung bawah yang tinggi pada perawat diakibatkan oleh salah satu faktor yaitu aktivitas fisik yang cukup berat, seperti melakukan aktivitas fisik seperti sering mengangkat pasien secara manual, dan memiliki jam kerja yang berlebih ditambah aktivitas diluar jam dinas dan waktu senggang. Sehingga hal tersebut menyebabkan spasme otot dan membuat saraf terhimpit kemudian timbulah rasa nyeri pada bagian punggung bawah.

Tabel 2.Distribusi responden Aktivitas fisik

\begin{tabular}{lll}
\hline Aktivitas Fisik & n & \% \\
\hline Rendah & 28 & 28 \\
Sedang & 31 & 31 \\
Tinggi & 41 & 41 \\
\hline Total & $\mathbf{6 8}$ & $\mathbf{1 0 0 , 0}$ \\
\hline
\end{tabular}

Sumber : Data Primer, 2018

Studi ini menunjukan bahwa perawat melakukan aktivitas fisik tinggi atau berat yaitu sebanyak $41 \%$, diikuti aktvitas fisik sedang $31 \%$ dan yang paling sedikit adalah aktivitas fisik rendah atau ringan yaitu sebanyak $28 \%$. Aktivitas berat atau tinggi yang di lakukan oleh perawat RSUD Luwuk Banggai seperti seperti sering mengangkat pasien, memindahkan pasien, jarang beristirahat sehabis melakukan tindakan, berolahraga berat diluar jam dinas dan jarang beritirahat, untuk aktivitas fisik sedang sama dengan aktivitas fisik berat namun intensitasnya tidak sesering aktivitas tinggi dan kegiatan diluar kerja dipakai untuk beristirahat dan untuk aktivitas ringan sebagian besar jarang melakukan aktivitas mengangkat atau memindahkan pasien, dan 
waktu diluar jam kerja dan senggang banyak digunakan untuk beristirahat. Hasil studi ini sesuai dengan hasil studi oleh beberapa peneliti, yang mengatakan bahwa seorang perawat memiliki aktivitas fisik yang berat karna perawat memiliki tanggung jawab melakukan aktivitas seperti mengangkat dan memindahkan pasien secara manual (Ovayolu et al, 2014).

Melihat dari hasil studi dan teori pendukung, Peneliti berasumsi bahwa aktivitas seorang perawat menjadi berat ini dikarenakan perawat memiliki tugas dan tanggung jawab yang besar diamana perawat harus merawat seorang pasien secara holistik dan menyeluruh. Peneliti juga berasumsi bahwa perawat di RSUD memiliki aktivitas yang berat karena selain sering melakukan aktivitas seperti mengangkat pasien, memindahkan pasien, dan jarang beristirahat sehabis melakukan tindakan, perawat RSUD Luwuk Banggai lebih banyak melakukan kegiatan diluar jam kerja dan jarang beristirahat diwaktu senggang. Kesimpulan dari hasil studi ini bahwa profesi perawat memiliki aktivitas fisik yang tinggi dikarenakan seorang perawat memiliki aktivitas fisik seperti aktivitas fisik tersebut seperti mengangkat pasien, memindahkan pasien secara manual, dan mengurus semua kebutuhan pasien, ditambah dengan aktivitas fisik diluar jam kerja seperti berolahraga berat dan jarang beritirahat diwaktu senggang.

Tabel 3. Analisis Hubungan Aktivitas Fisik dengan Nyeri Punggung Bawah pada Perawat di Rumah Umu Daerah Luwuk Banggai

\begin{tabular}{|c|c|c|c|c|c|c|c|}
\hline \multirow{3}{*}{$\begin{array}{c}\text { Aktivitas } \\
\text { Fisik }\end{array}$} & \multicolumn{6}{|c|}{ Kelancaran ASI } & \multirow{3}{*}{$\begin{array}{c}\rho- \\
\text { Value }\end{array}$} \\
\hline & \multicolumn{2}{|c|}{$\begin{array}{c}\text { Tidak } \\
\text { Terdiagnosa }\end{array}$} & \multicolumn{2}{|c|}{ Terdiagnosa } & \multicolumn{2}{|c|}{ Total } & \\
\hline & $\mathrm{n}$ & $\%$ & $\mathrm{n}$ & $\%$ & $\mathrm{n}$ & $\%$ & \\
\hline Rendah & 20 & 20 & 8 & 8 & 28 & 28 & \multirow{3}{*}{0,001} \\
\hline Sedang & 12 & 12 & 20 & 20 & 32 & 32 & \\
\hline Tinggi & 10 & 10 & 30 & 30 & 40 & 40 & \\
\hline Total & 42 & 42 & 58 & 58 & 100 & 100 & \\
\hline
\end{tabular}

Sumber : Data Primer, 2018

Analisis uji hipotesis chi-square dengan tingkat kepercayaan $95 \% \quad\left(\begin{array}{ll}\alpha & 0,05\end{array}\right)$, menunjukan adanya hubungan yang signifikan antara aktivitas fisik dan nyeri punggung bawah dimana nilai $p$-value $=$ 0,001 lebih kecil dari $\alpha=0,05$. Dengan demikian sesuai dengan dugaan awal peneliti bahwa terdapat hubungan antara aktivitas fisik dan nyeri punggung bawah pada perawat di RSUD Luwuk Banggai. Hasil studi ini sesuai dengan studi cross sectional telah dilakukan oleh Rezae \& Gasemi (2014), di Iran. Bin-Homaid et al, (2016), di Arab. Savic, \& Touzery (2017), di Slovenia. Dlungwange, Voce \& Knight (2018), di Afrika Selatan. mereka menggunakan metode cross sectional dan menemukan bahwa aktivitas fisik perawat memiliki hubungan yang kuat dengan nyeri punggung bawah. Namun hasil studi ini berbeda dengan hasil studi cross sectional oleh Asadi, Kasmaei, Ziabari, dan Zohrevandi (2016) dan hasil studi dari Frantz (2012), mereka menemukan hasil yang berbeda, dimana aktivitas fisik tidak memiliki hubungan bermakna dengan nyeri punggung bawah.

Penelitian pada studi ini, menunjukan terdapat 30 perawat yang melakukan altivitas fisik berat, terdiagnosa nyeri punggung bawah. 20 perawat yang melakukan altivitas fisik sedang terdiagnosa nyeri punggung bawah, dan 20 perawat yang melakukan aktivitas fisik rendah, tidak terdiagnosa nyeri punggung bawah. Hasil ini sejalan dengan teori pendukung oleh Gibson, (2012), dimana nyeri punggung bawah banyak terjadi pada perawat yang memilki aktivitas yang sedang hingga berat sehingga dapat menyebabkan stress fisik yang berlebihan pada sumsum tulang beawah dan spasme otot kemudian mengalami penekanan nervus dibagian lumbalis sehingga perawat merasakan nyeri dibagian punggung bawah, sebaliknya jika aktivitas rendah atau ringan maka nyeri tidak akan timbul karena otos tidak mengalami spasme dan membuat saraf terhimpit.

Data pada studi ini juga ditemukan 8 responden yang melakukan aktifitas fisik rendah atau ringan terdiagnosa nyeri punggung bawah. Hal ini dapat disebabkan 
oleh faktor usia dan jenis kelamin perawat, sesuai teori oleh Satyanegara et al, (2010), kejadian Nyeri punggung bawah mengalami peningkatan dan akan semangkin meningkat seiring dengan bertambahnya usia dimana saraf-saraf punggung bawah mengalami proses degenerative dan otot megalami penurunan elastisitas yang menyebabkan kekakuan otot berujung pada penghimpitan saraf dan menimbulkan nyeri dibagian punggung bawah.

Kemudian ditemukan juga 10 responden yang melakukan aktifitas fisik tinggi tidak terdiagnosa nyeri punggung bawah dan 12 responden yang melakukan aktifitas fisik sedang tidak terdiagnosa nyeri punggung bawah. Hal ini terjadi karna manfaat dari beraktifitas fisik dapat membuat perubahan peningkatan kekuatan otot termasuk pada komponen neural maupun muskular (World Health Organization, 2018). Perubahan dari otot ini menyebabkan tubuh lebih tahan terhadap stress mekanik, sehingga orang yang sering melakukan aktivitas fisik sedang maupun tinggi diharapkan tidak mengalami nyeri punggung bawah (Pirade, 2013).

Melalui hasil studi dan teori pendukung ditemukan bahwa terdapat hubungan yang signifikan dan hubungan sebab akibat antara aktivitas fisik dengan nyeri punggung bawah pada perawat di RSUD Luwuk Banggai. Peneliti berasumsi bahwa aktivitas fisik memiliki hubungan yang signifikan dengan nyeri punggung bawah pada perawat di RSUD Luwuk Banggai dikarenakan seorang perawat memiliki aktivitas fisik yang cukup berat, seperti sering mengangkat pasien secara manual, dan memiliki jam kerja yang berlebih ditambah aktivitas diluar jam dinas dan waktu senggang yang jarang digunakan untuk beristrahat dari aktivitas fisik yang cukup berat dan padat ini dapat menyebabkan perubahan pada otot skeletal yaitu stress dan ketegangan otot mengakibatkan penghimpitan otot saraf, (Satyanegara et al, 2010). dan menyebabkan timbulnya rasa nyeri pada bagian punggung bawah perawat (Gibson, 2012). Peneliti juga berasumsi bahwa adanya perbedaan dalam hasil studi antara aktivitas fisik dan nyeri punggung bawah dikarenakan alat ukur aktivitas fisik yang berbeda.Kesimpulan dari hasil studi ini ditemukan bahwa terdapat hubungan yang signifikan aktivitas fisik baik sedang maupun berat dapat menyebabkan nyeri punggung bawah pada perawat di RSUD Luwuk Banggai dikarenakan perawat RSUD Luwuk Banggai sering melakukan aktivitas fisik dengan intensitas sedang sampai tinggi seperti sering mengangkat pasien secara manual, membungkuk untuk mengubah posisi pasien, dan memiliki jam kerja yang berlebih ditambah aktivitas diluar jam dinas dan waktu senggang yang jarang digunakan untuk beristrahat dari aktivitas fisik yang cukup berat dan padat ini dapat menyebabkan peningkatan ketegangan otot dan mengakibatkan penghimpitan otot saraf, dan menyebabkan timbulnya rasa nyeri pada bagian punggung bawah perawat.

\section{SIMPULAN}

Hasil kesimpulan dari pembahasan tentang hubungan aktivitas fisik dengan nyeri punggung bawah pada perawat di Rumah Sakit Umum Daerah Luwuk Banggai, bahwa sebagian besar perawat mengalami nyeri punggung bawah, sebagian besar perawat memiliki aktivitas fisik yang tinggi atau berat. dan terdapat hubungan yang signifikan antara aktivitas fisik dengan nyeri punggung bawah pada perawat di Rumah Sakit Umum Daerah Luwuk Banggai.

\section{DAFTAR PUSTAKA}

Asadi, Kasmaei, Ziabari, \& Zohrevandi (2016). The prevalence of low back pain among nurses working in Poursina hospital in Rasht, Iran. Journal of Emergency Practice and Trauma.Diakses pada tanggal 6 Desember 2018 
Asmadi. (2008). Teknik Prosedural Keperawatan : Konsep dan Aplikasi Kebutuhan Dasar Klien. Jakarta : Salemba Medika

Bin Homaid et, al. (2016). Prevalence and risk factors of low back pain among operation room staff at a Tertiary Care Center, Makkah, Saudi Arabia: a crosssectional study. Ann Occup Environ Med. Diakses pada tanggal 6 desember 2018.

Boughattas, et al. (2017). Low Back Pain among Nurses: Prevalence, and Occupational Risk Factors. Scientific Research Publishing. Diakses pada tanggal 17 Oktober 2018

Dlungwane, Voce, \& Knight (2018). Prevalence and factors associated with low back pain among nurses at a regional hospital in KwaZulu-Natal, South Africa. Health SA Gesondheid. Diakses pada tanggal 6 Desember 2018.

Frantz, Lela M. (2012). The Relationship Between Low Back Pain and Physical Activity Among Nurses in Kanombe Military Hospital. Research Gate.Diakses pada taggal 5 Desember 2018

Gibson, John. (2012). Fisiologi dan Anatomi Modern Untuk Perawat. Jakarta: EGC

Goni, Naftalia. (2016). Karateristik perawat di Irina F RSUP Prof. Dr. R. D. Kandou Manado yang mengalami keluhan nyeri punggung bawah. e-journal UNSRAT.Diakses pada tanggal 25 September 2018

Ovayolu, et al (2014). Frequency and severity of low back pain in nurses working in intensive care units and influential factors. Pakistan Journal of Medical Sciences. Diakses pada tanggal 20 september 2018
Pirade, Aron. (2013). Hubungan posisi dan lama duduk dengan nyeri punggung bawah (npb) mekanik kronik pada karyawan bank. e-journal UNSRAT.Diakses pada tanggal 6 Desember 2018

Rezaee \& Ghasemi. (2014). Prevalence of Low Back Pain Among Nurses : Predisposing Factors and Role of Work Place Violence. Trauma Monthly : Journal of Trauma and Emergency Medicine.Diakses pada tanggal 20 September 2018

Sanjoy, Shubrandu, et, al. (2017). Occupational factors and low back pain: a cross-sectional study of Bangladeshi female nurses. BioMed Central.Diakses pada tanggal 20 September 2018. Diakses pada tanggal 20 September 2018

Savic, \& Touzery. (2017). Low back pain among nurses in Slovenian hospitals: cross-sectional study. International Nursing Review. Diakses pada tanggal 20 September 2018

Satyanegara, et al. (2010). Ilmu Bedah Saraf Edisi IV. Jakarta : PT.Gramedia Pustaka Utama

Shwn-Huey Shieh, et, al. (2016). Increased low back pain risk in nurses with high workload for patient care: A questionnaire survey. Taiwanese Journal of Obstetrics \& Gynecology. Diakses pada tanggal 17 Oktober 2018 